\title{
La guerra interna de Marx. Análisis de su intento por superar la teleología de la historia desde sus reflexiones sobre la periferia del mercado mundial capitalista*
}

Fecha de entrega: 28 de octubre de 2018 Fecha de evaluación: 11 de diciembre de 2018

Fecha de aprobación: 30 de enero de 2019

\section{Carlos Maximiliano Macías Fernández**}

\section{Resumen}

En los estudios de Marx sobre el modo de producción específicamente capitalista en la periferia, más allá de Europa occidental, encontramos un doble movimiento: sus estudios históricos configuran todo un campo de tensiones en el que podemos examinar sus posiciones políticas y teóricas entrecruzadas con los cambios y las contradicciones históricas del siglo xIx. Analizando las opiniones de Marx sobre la cuestión colonial y la cuestión nacional en casos tan variados como los de India, América Latina, China, Irlanda, Polonia o Rusia comprobamos su distanciamiento creciente pero irregular con respecto al "sistema" hegeliano, que nunca dejó de inspirarlo, en un intento de superar la

* Este artículo se basa en una versión preliminar presentada y discutida en el Coloquio Internacional Marx e o Marxismo, 21-25 de agosto de 2017, Universidade Federal Fluminense, Río de Janeiro (Brasil). Agradezco a los participantes en la mesa del coloquio "Os limites da crítica tradicional: o que as periferias podem dizer sobre?" por las críticas y los aportes recibidos. Citar como: Macias Fernández, C. M. (2019). La guerra interna de Marx. Análisis de su intento por superar la teleología de la historia desde sus reflexiones sobre la periferia del mercado mundial capitalista. Cuadernos de Filosofía Latinoamericana, 40(121), 161-188. DOI: https://doi.org/10.15332/25005375.5476

* Economista, doctor en Geografía por la Universidade Estadual Paulista (UnESP), São Paulo (Brasil). Profesor del Doctorado en Ciencias Sociales, Niñez y Juventud del Centro de Estudios Avanzados en Niñez y Juventud, Manizales (Colombia).Correo electrónico: carlosmaxmf@gmail.com 
teleología de la historia. En cuestionamiento se encontraba el presupuesto de que las formas sociales superiores surgen del agotamiento y la aniquilación de las directamente inferiores. Aunque imperfecta, la superación de la teleología acercó a Marx al reconocimiento de la coexistencia en el espacio y en el tiempo de formas sociales heterogéneas, lo que apuntaba hacia una concepción diferente de la teoría y la acción política.

Palabras clave: forma social, periferia, teleología, epistemología marxista.

Marx's Internal Struggle. An Analysis of his Attempt to Overcome the Teleology of History on the basis of his Reflections on the Periphery of the Capitalist World Market

\section{Abstract}

Marx's studies regarding the specifically capitalist mode of production in the periphery, beyond Western Europe, reveal a double movement: his historical studies give rise to a field of tensions in which we can examine his political and theoretical positions, intertwined with the changes and historical contradictions of the $19^{\text {th }}$ century. The analysis of his opinions on the colonial question and the national question, in such varied cases as those of India, Latin America, China, Ireland, Poland, or Russia, shows his increasing, yet irregular distance from the Hegelian "system", which never ceased to inspire him, in an effort to overcome the teleology of history. Marx questioned the assumption that higher social forms arise from the exhaustion and destruction of the immediately lower ones. Despite its imperfection, Marx's overcoming of teleology led him to recognize the coexistence in space and time of heterogeneous social forms, thus pointing toward a different conception of theory and political action.

Keywords: social form, periphery, teleology, Marxist epistemology. 


\section{Introducción}

A doscientos años del nacimiento de Marx sigue resultando un problema comprender el papel que jugó una cierta concepción teleológica de la historia en su formación intelectual y en su propuesta teórica. Se trata de un problema difícil de estudiar porque Marx abordó esta cuestión desde diferentes perspectivas a lo largo de su trayectoria intelectual, con lo cual permitió lecturas contradictorias de su obra. Además, como dice Tarcus (2008), gran parte de los aportes teóricos posteriores en la tradición marxista mantuvieron vivo el problema al chocar de manera más o menos expresa con el supuesto de una filosofía de la Historia en cualquiera de sus manifestaciones. Lo cierto es que, hasta el final de su vida, Marx nunca dejó de librar consigo mismo una guerra que no llegó a ganar del todo.

En su sentido más sencillo podemos considerar que la teleología de la que partía Marx consistía en tomar la Historia - con mayúscula - como un proceso continuo en el que unas formas sociales llegan a su fin para ser relevadas o desplazadas por otras superiores. De esta manera, se supondría un orden lógico y necesario, y por eso preexistente, que se hace presente en el orden empírico longitudinal y temporal para completar así un sentido latente desde siempre en la Historia. En el caso de Marx y la tradición que nace con él, este orden lógico coincide con la teoría, la cual nos permite prever el final al que se dirige el orden empírico. El fin de la Historia consistiría en el comunismo como sinónimo de desaparición de la explotación de unos miembros de nuestra especie por otros. Con el comunismo acabaría la Historia, o en otro sentido, acabaría "la prehistoria de la sociedad humana" (Marx, 2008a, p. 6).

El contenido de esta Historia en movimiento son las formas sociales, entendidas como los modos sociales y relacionales de producir y distribuir la riqueza. Si no hubiera formas sociales cambiantes, no se podría hablar estrictamente de Historia porque fuera de la sucesión de estas lo que encontramos son las mismas formas naturales en las que el ser humano se relaciona con la naturaleza, como un ser necesitado que transforma su medio para reproducirse. A esta relación esencialmente estable con la naturaleza para cualquier momento y lugar Marx la denominó "proceso de trabajo". Lo que resulta específico de cada momento histórico son las formas sociales que revisten el proceso de trabajo, que Marx denominó "proceso de valorización” 
en la sociedad capitalista (Marx, 1975a). La estructura teóricamente racional en la que las formas sociales del capital (salario, valor, fuerza de trabajo, dinero, etc.) se relacionan es la clave para la superación de un momento dado, es decir, del estado actual del orden empírico ${ }^{1}$.

Sin embargo, una obra compleja y dilatada en el tiempo como la de Marx está más próxima a comportarse como un "campo de fuerzas" que como un orden lógicoteórico abstracto y armonioso. De hecho, la norma es la coexistencia conflictiva de nociones y categorías contradictorias que pugnan continuamente por adaptarse entre sí en versiones lo más coherentes posible, pero excluyentes unas de otras. Uno de los motores de esta pugna entre concepciones teóricas en la obra de Marx fue su intento de abandonar el supuesto teleológico - que llegó a ser percibido eventualmente como un escollo a superar - sin pagar a cambio el precio de renunciar al horizonte comunista que la teleología garantizaba. Solo hacia el final de su vida Marx casi consigue presentar, aunque de manera aún tímida, una lectura no teleológica de la Historia que permitía salvaguardar la aspiración comunista.

Haciendo una breve reconstrucción histórico-geográfica de los estudios de Marx sobre lo que podríamos llamar la periferia del mercado mundial estaremos en mejores condiciones de comprender la guerra interna que libró contra la teleología. Sin embargo, debemos comenzar por mostrar de qué modo el presupuesto teleológico fue tanto una ventaja como luego un problema en el pensamiento de Marx.

\section{La pertinencia de la teleología en la formulación del pensamiento temprano de Marx}

En la famosa carta Weydeymeyer del 5 de marzo de 1852 Marx no plantea la teleología como problema, sino como aquello que fue felizmente descubierto, o mejor dicho, justificado científicamente y no desde la especulación filosófica:

1 Por eso El capital es esencialmente la presentación de un sistema categorial (Dussel, 2014), es decir, un orden lógico-teórico que nos permite entender las formas sociales del capital en sus relaciones. Y no debe confundirse con la realidad histórica (el orden empírico), aunque sea en esta donde efectivamente sean producidas y transformadas dichas formas sociales. 
Lo nuevo que he aportado al respecto es: 1) demostrar que la existencia de clases va aparejada a fases históricas determinadas del desarrollo de la producción; 2) que la lucha de clases conduce necesariamente a la dictadura del proletariado; 3) que dicha dictadura no representa sino una transición hacia la abolición de todas las clases y hacia una sociedad sin clases. (Marx y Engels, 1983, p. 62; énfasis en el original)

Efectivamente, Marx afirma que lo que "conduce necesariamente" ha sido garantizado por un conocimiento científico de la Historia, y eso fue un aporte heredado y aprovechado - e incluso salvado- de la tradición filosófica hegeliana en la que se había formado. Esta baza permitía a Marx romper con un socialismo anterior de tipo moralista (o superarlo, desde esa perspectiva), que genéricamente se etiquetó como "socialismo utópico".

Como ejemplo de esta disputa teórica con las corrientes utopistas del socialismo podemos recordar que el programa de 1838 de la Liga de los Justos —el grupo político al que Marx y Engels se aproximaron desde 1844, unos años antes de que pasara a refundarse como la Liga de los Comunistas- era el manifiesto del socialista alemán Wilhelm Weitling titulado "La humanidad tal como es y tal como debería ser". En sus recuerdos de 1885 Engels (1974) explica que en la década de 1840 él mismo y Marx estaban llegando en paralelo a la misma conclusión: que las luchas políticas eran luchas de clases y que en ese momento histórico estaba surgiendo el proletariado como nueva clase producto de la gran industria. De esa manera, Engels diferenciaba las propuestas teóricas dentro de la Liga. Por un lado la que encuentran al llegar, con la figura paradigmática de Weitling, que contrapone el ser histórico con el deber moral. Por otro lado, la nueva propuesta teórica de Marx y del mismo Engels, a la que estaban llegando por caminos paralelos, en la que el futuro no es un deber moral externo sino algo que nace del presente.

Engels estaba llegando a la centralidad de la nueva clase proletaria como nueva forma social revolucionaria de la Historia en su estudio La condición de la clase obrera en Inglaterra (publicado en 1845 pero escrito entre 1843 y 1844). Marx lo había planteado en términos filosóficos en la crítica a Hegel publicada en los Anales FrancoAlemanes de 1844. El "descubrimiento" en paralelo - una serendipia teórica- de los dos pensadores solo podía oponerse al utopismo de pensadores como Weitling porque se apoyaban en la necesidad histórica de las formas políticas revolucionarias que 
estaban surgiendo - como el comunismo en Francia o el cartismo en Inglaterra-, manifestaciones de un devenir inmanente, teleológico, de la Historia:

Estos movimientos se presentaban ahora como un movimiento de la moderna clase oprimida, del proletariado, como formas más o menos desarrolladas de su lucha históricamente necesaria contra la clase dominante, contra la burguesía; como formas de la lucha de clases, pero que se distinguían de todas las luchas de clases anteriores en que la actual clase oprimida, el proletariado, no puede llevar a cabo su emancipación, sin emancipar al mismo tiempo a toda la sociedad de su división en clases, y por tanto, de la lucha de clases. Ahora, el comunismo ya no consistía en exprimir de la fantasía un ideal de la sociedad lo más perfecto posible, sino en comprender el carácter, las condiciones y, como consecuencia de ello, los objetivos generales de la lucha librada por el proletariado. (Engels, 1974, p. 190)

La tradición hegeliana en la que se inscribían tanto Marx como Engels proporcionaba un recurso muy valioso para evitar caer en la dicotomía entre lo positivo y lo normativo del socialismo utópico. Desde esta perspectiva, el proyecto revolucionario no sería alguna idea externa que llega para corregir el estado de cosas vigente, sino aquello que surge en el seno mismo de la Historia en movimiento porque a lo que nos dirigimos es en sí mismo algo que ya forma parte, larvadamente, de tal estado. Esto ya presente en la Historia es su propia negatividad, que tiende a surgir para superar lo dado, lo positivo.

Lo vemos claramente expresado por Marx en su carta a Ruge de septiembre de 1843. El crítico es definido allí como aquel que parte de las "propias formas de la realidad existente" (Marx, 1985a, p. 459), y a partir de las formas de conciencia teórica y práctica desarrolla su crítica a la razón ya presente hasta realizarla por completo porque "la razón siempre ha existido, aunque no siempre bajo forma racional" (p. 458). De ahí la definición del comunismo como una fuerza que anula lo existente desde sus entrañas y no un dogma que se impone desde fuera:

Para nosotros, el comunismo no es un estado que debe implantarse, un ideal al que haya de sujetarse la realidad. Nosotros llamamos comunismo al movimiento real que anula y supera al estado de cosas actual. Las condiciones de este movimiento se desprenden de la premisa actualmente existente. (Marx y Engels, 1974, p. 37) 
Entendemos entonces que el joven Marx estuviera interesado en una perspectiva teleológica capaz de justificar el comunismo como algo que se encuentra ya presente en la propia Historia, algo que es resultado del mismo desarrollo de la Historia, como una potencialidad que se realiza. Eso que viene a confrontar o a negar el estado de cosas actual es algo que en rigor todavía no existe porque es una dinámica que solo se completará en el tiempo. Lo que luego acabaría denominándose socialismo científico frente al voluntarismo utópico necesitaba una cierta teleología que tuviera como base la filosofía hegeliana de tomar la verdad por el todo y considerar al movimiento más real que lo empíricamente existente. Por eso, en un primer momento, Marx y Engels se apoyaron en una crítica filosófica de la ciencia positiva, que se preguntaba únicamente por lo ya dado en el presente. Frente a esa ciencia positiva lo que plantearon los dos jóvenes pensadores fue una ciencia crítica que aspira a descubrir las potencialidades presentes que explican los cambios y permiten prever el futuro.

Por lo tanto, resulta comprensible que al joven Marx el recurso a la teleología de la Historia le resultara sumamente útil para combatir las corrientes utópicas del socialismo del momento. Esta concepción teleológica permitía desechar el moralismo al presentar el horizonte comunista como una necesidad insoslayable y no como una especie de imperativo categórico kantiano.

\section{Las tres herencias de la teleología en la Historia}

La teleología hegeliana de la que partía Marx tomaba lo racional como una realidad esencial que va manifestándose al adoptar sucesivas formas materiales a lo largo de un proceso ordenado. A grandes rasgos, Hegel había traducido al idealismo laico alemán tres influencias previas. Es pertinente revisarlas brevemente para poder conjugarlas.

La más directa influencia era la solución que Kant había encontrado al problema de la inducción. Como es bien sabido, Hume había mostrado que la inducción no puede ser garantía de un conocimiento cierto. La solución de Kant fue garantizar la certeza gracias a la actividad del ser humano, que coloca en el objeto el contenido que él mismo va a conocer después, es decir, que va a reconocer. El ser humano no tiene acceso al noúmeno, pero sí al fenómeno, que él mismo construye por medio de su actividad intelectual. De aquí vendrá la noción de que conocer es algo práctico para el ser humano - una práctica intelectual en este caso- y no un simple reflejo pasivo del mundo exterior. 
Anteriormente la tradición escolástica medieval había mantenido vivo el realismo platonista, que consideraba que lo real es aquello que funda el contenido racional y cognoscible de la cosa existente. No siendo ajeno a esta tradición, para Hegel la verdad de algo es ese contenido "real”, que no se confunde con su apariencia empírica, aunque necesariamente solo podamos conocer la primera a través de la segunda.

Por último, como bien recoge Rendueles (2012), no podemos ignorar la supervivencia de la teodicea cristiana en su intento de explicar la pervivencia del mal en el mundo a pesar de la omnipotencia de un Dios bondadoso. La teodicea traía la idea de pensar el objeto de conocimiento como proceso y no como un estado de cosas ya dado y pasivo. Al traducir este problema del punto de vista teológico al filosófico, resulta esperable que en la realidad empírica siga persistiendo lo irracional en un proceso gradual de sustitución por lo racional. Si para la teodicea la "verdad" de Dios es un proceso que desplaza paulatinamente al mal, ahora es lo "racional" aquello que desplaza en el proceso a lo "irracional". Lo irracional queda relegado a aquello que no precisa ser explicado, o cuanto más, su único papel en la Historia es el de ir desapareciendo lentamente.

A partir de estos elementos, que seguían perdurando en Hegel, Marx hará una síntesis entre la tradición materialista y la idealista, tal como la encontramos en las “Tesis sobre Feuerbach”. En esa síntesis Marx considera superado el materialismo pasivo gracias al elemento activo idealista del sujeto que crea el mundo. Solo que, según el materialismo, lo racional que el ser humano coloca en el mundo no es una operación intelectual de conocimiento, sino una operación de creación material del mundo que se denominará praxis. Lo racional será un proceso por el cual la praxis va eliminado lo irracional del mundo y creando así un nuevo mundo racional. Lo producido por la praxis son las formas sociales, que en cada etapa histórica superan sus versiones anteriores, de modo que alcanzan siempre un grado de mayor racionalidad. De esta manera, la teleología como proceso predestinado por una conciencia divina superior desaparece y en cambio se otorga agencia al ser humano.

Así, Marx parte de un punto en el que está lejos de contar con una verdadera alternativa a la teleología que no pusiera en riego la garantía de un horizonte comunista. Será la publicación de El origen de las especies de Darwin en 1859 - mismo año en que Marx publica la Contribución para la crítica de la economía política- lo que permitirá al de Tréveris comenzar a pensar teóricamente la superación de las formas 
sociales sin una teleología que presuponga un orden prefijado, o sea, sin precisar de un orden teórico preexistente que estuviera siendo materializado por los hombres en el orden histórico. En una carta a Lassalle fechada el 16 de enero de 1861 Marx afirma que el único motor verdadero sería la lucha de clases:

El libro de Darwin es muy importante y me sirve de base de la lucha de clases en la historia. Desde luego que uno tiene que aguantar el crudo método inglés de desarrollo. A pesar de todas las deficiencias, no sólo se da aquí por primera vez el golpe de gracia a la "teleología” en las ciencias naturales, sino que también se explica empíricamente su significado racional. (Marx y Engels, 1975, p. 23)

Aunque Marx en el futuro criticará a Darwin por considerar que reproduce en su interpretación de la naturaleza los prejuicios del pensamiento social burgués (sobre todo los de Hobbes, Malthus y los supuestos de la competencia capitalista), el inglés fue una influencia fundamental que permitió al alemán aceptar que no existe una lógica autónoma materializándose en la Historia, sino un orden que se ajusta a las necesidades históricas resueltas por la lucha de clases. Por lo tanto, la necesidad no desaparece de la Historia. De lo que se trata es de sustituir su sustrato metafísico por uno material: la necesidad es la lucha de clases misma.

\section{Las etapas del pensamiento de Marx sobre la expansión del capitalismo}

Para comprender mejor la manera en la que Marx fue transitando desde la teleología de la Historia hasta su crítica, procedemos a reconstruir algunos momentos de su biografía intelectual en los que estudió la expansión del capitalismo. Son ocasiones en las que Marx pudo corroborar la pertinencia o impertinencia de un presupuesto teleológico, y por ello, oportunidades y motivaciones para modificar su comprensión teórica de la sociedad.

\section{Alemania, de periferia a cuna de la próxima revolución}

Desde su exilio temprano Marx estaba esperando que Alemania fuese la nueva cuna de la revolución, de tal manera que la madurez intelectual de su país natal se viera finalmente acompañada por la superación de una institucionalidad que seguía 
arrastrando la impronta del feudalismo. Esas esperanzas fueron frustradas por el resultado tan limitado de la revolución de 1848 en Alemania.

La pregunta pertinente es de qué manera Marx podía justificar ese papel protagonista que habría de tener Alemania dado su retraso en el desarrollo de las relaciones capitalistas en comparación con Francia, Bélgica o Inglaterra. Lo cierto es que la periferia y el papel de lo periférico estuvieron siempre presentes en el pensamiento de Marx, y aquí se comprueba. Para él, era precisamente esa posición periférica de Alemania frente al desarrollo general de la humanidad lo que le permitía esperar grandes contribuciones de su país (que ni siquiera estaba unificado en aquel momento): "Los alemanes han pensado lo que los otros pueblos han hecho. Alemania ha sido su conciencia teórica. La abstracción y elevación de su pensamiento marcharon siempre a igual paso con la unilateralidad y la humildad de su vida real" (Marx, 1968, p. 15).

La superación tiene su origen, por lo menos en cuanto que proyecto intelectual, en la periferia del capital en aquel momento: Alemania. No obstante, es cierto que Marx estaba pensando que la revolución socialista sería una revolución del proletariado inglés o del francés. La posición periférica de Alemania daba a los comunistas alemanes el papel de aliados de la burguesía en esa próxima e inminente revolución, tal como lo propone Marx en el Manifiesto de 1848. Pero ocurre que en la perspectiva teleológica del desarrollo histórico el eje temporal es la clave, aún más importante que las realidades concretas, de tal modo que las últimas luchas obreras que tienen lugar en la periferia muestran mayor madurez. Por eso, si bien las condiciones históricas concretas de Alemania no estaban preparadas para la revolución socialista, la conciencia obrera como superación del capitalismo surgía allí debido a las condiciones más extremas y el aprendizaje (o superación) de las experiencias previas en otros lugares. El caso específico lo tenemos en 1844 con la rebelión de los tejedores en Silesia, en el oriente de Prusia, lindando con Polonia y lo que hoy es la República Checa, auténtica periferia de la periferia en aquel momento. Marx defendió el carácter político y revolucionario de los tejedores que protagonizaron la revuelta en esa alejada región frente a aquellos que consideraban aquel episodio como lo que hoy se denominaría protopolítica:

La insurrección silesiana comienza precisamente por donde habían terminado las revueltas obreras de Francia e Inglaterra, por la conciencia acerca de la esencia misma del proletario. Y la misma acción revela este carácter de 
superioridad. No son destruidas solamente las máquinas, rivales del obrero, sino que los sublevados destruyen también los libros comerciales y los títulos de propiedad, y mientras que todos los demás movimientos solo iban dirigidos en primer término contra el empresario industrial, contra el enemigo ostensible, el movimiento silesiano se dirige también contra el banquero, el enemigo encubierto. Por último, ninguna insurrección inglesa ha dado tales pruebas de valentía, reflexión y perseverancia. (Marx, 1985b, p. 516)

Por tanto, formalmente Marx está esperando la revolución socialista en el Occidente, pero la superación constante de las formas sociales permite considerar la posibilidad de una rápida sucesión desde la periferia. Por eso en 1850 - antes de aceptar que el ciclo revolucionario de 1848 se había agotado- Marx usa por primera vez el concepto de "revolución permanente" (Marx y Engels, 1973), o sea, la posibilidad de una rápida sucesión de formas, tal que la atrasada Alemania alcance rápidamente a la adelantada Inglaterra.

En ese momento temprano de su biografía la teleología permite a Marx sostener la hipótesis política de la superación desde la periferia, sin contradecir por ello la sucesión ordenada de formas sociales. El problema será cuando las expectativas de Marx no queden satisfechas por los acontecimientos históricos.

\section{El mercado mundial desde los primeros trabajos}

Lichtheim (1961) ha señalado que el fracaso de las revoluciones de 1848 llevó a la separación nítida del movimiento socialista y el movimiento burgués, antiguos socios en un movimiento democrático que se demostró incapaz de resolver la "cuestión social". La derrota del 48 fue reinterpretada por Marx no como una falsación completa de la teoría recién inaugurada, sino como la prueba de que aún quedaba ese penúltimo paso político por dar en la Historia antes de alcanzar las condiciones para una verdadera revolución socialista. Así, la tarea histórica de 1848, a pesar del fracaso revolucionario, se cumplió satisfactoriamente al permitir la división en el campo político entre los dos futuros enemigos íntimos: burguesía y proletariado. En la nueva situación Marx se hizo consciente de las condiciones que desencadenan un periodo revolucionario, y profundizó en su estudio de la economía política, pero también en la comprensión del moderno "mercado mundial". 
De hecho, tenemos de Marx una especie de “concepción heredada” que nos lo presenta como alguien tan solo marginalmente interesado por la periferia del capitalismo. No obstante, pensar en dicha periferia más allá de Europa era una necesidad en Marx porque desde el comienzo reconoció el surgimiento de un "mercado mundial”. Y esa preocupación continuó. Es más, sabemos que en su plan de trabajo original para $E l$ capital estaba escribir un libro dedicado a esto ${ }^{2}$.

También sabemos que Marx nunca planeó dedicar tanto tiempo a escribir el contenido que finalmente fue parcialmente presentado en El capital. Eran otros temas los que atraían su atención y el estudio de la economía política le parecía aburrido y limitado, como confiesa a Engels en carta del 2 de abril de 1851:

He avanzado tanto que, dentro de cinco semanas, habré terminado con toda esta porquería de la economía. Et cela fait [Una vez hecho esto], es en casa donde redactaré la Economía política, mientras que en el Museum [Museo] me dedicaré a otra ciencia. Ça commence a mienuger [Esto comienza a aburrirme]. Au fond [En el fondo], esta ciencia, desde A. Smith y D. Ricardo, no ha progresado más, a pesar de todas las investigaciones particulares y a menudo sumamente delicadas a que se la ha sometido. (Marx y Engels, 1983, pp. 51-52)

Desde ese momento Marx siempre fue anunciando que sus estudios de economía política estaban llegando a su fin, hasta que en el momento de publicar el primer libro de El capital reconoció cuánto se había confundido en sus cálculos ${ }^{3}$. En todo ese tiempo el interés de Marx por la expansión del capitalismo no fue un simple ho$b b y$, sino una parte del análisis del moderno mercando mundial capitalista. La clave está en las diversas maneras en las que Marx intentó conceptualizar dicho mercado.

En sus primeros trabajos la fuerte lectura hegeliana todavía presente lo hizo entender el mercado mundial como "historia universal" que surge o emerge. Pero tal historia no es una realidad que siempre existió, ni tampoco una invención o una lectura teórica analítica que hacemos del pasado desde el presente. En la Introducción de 1857 Marx dirá de nuevo literalmente que "la historia universal no siempre existió; la

2 Tal como Marx manifiesta en su carta a Lassalle del 22 de febrero de 1858, y al poco tiempo hace público en el "Prólogo" a la Contribución de 1859.

3 Ver, por ejemplo, la carta a Kugelmann del 13 de julio de 1867 (Marx, 1975b, pp. 57-58). 
historia como historia universal es un resultado" (2008b, p. 311). Se trata, por tanto, de una nueva relación entre los seres humanos, que compartimos un mismo destino desde que el capital nos ha conectado en un sistema mundial. Ese sería el primer sentido del mercado mundial. Sin embargo, Marx es perfectamente consciente de la realidad material de ese proceso, por ejemplo, en sus elementos tecnológicos y en los efectos perversos que podría tener. Veamos dos casos: 1) la máquina fabricada en Inglaterra que puede provocar desempleo en China e India y 2) la escasez de azúcar y café que puede llevar a los alemanes a sublevarse contra Napoleón:

Va la historia convirtiéndose en historia universal, y así vemos que cuando, por ejemplo, se inventa hoy una máquina en Inglaterra, son lanzados a la calle incontables obreros en la India y en China y se estremece toda la forma de existencia de estos países, lo que quiere decir que aquella invención constituye un hecho histórico-universal; y vemos también cómo el azúcar y el café demuestran en el siglo XIX su significación histórico-universal por cuanto la escasez de estos productos, provocada por el sistema continental napoleónico, incitó a los alemanes a sublevarse contra Napoleón, estableciéndose con ello la base real para las gloriosas guerras de independencia de 1813. (Marx y Engels, 1974, p. 50)

En las palabras de Marx vemos que la "historia universal" consiste en la aparición de una nueva realidad material, mucho más allá de "un simple hecho abstracto de la 'autoconciencia"'. La Humanidad era entonces un colectivo único, y la única respuesta a nuestros problemas sería un futuro común. Esta cuestión es tan importante para Marx que así aparece en la definición misma de comunismo citada anteriormente:

Para nosotros, el comunismo no es un estado que debe implantarse, un ideal al que haya de sujetarse la realidad. Nosotros llamamos comunismo al movimiento real que anula y supera al estado de cosas actual. Las condiciones de este movimiento se desprenden de la premisa actualmente existente. Por lo demás, la masa de los simples obreros - de la fuerza de trabajo excluida en masa del capital o de cualquier satisfacción, por limitada que ella sea- y, por tanto, la pérdida no puramente temporal de este mismo trabajo como fuente segura de vida, presupone, a través de la competencia, el mercado mundial. Por tanto, el proletariado sólo puede existir en un plano histórico-mundial, lo mismo que el comunismo, su acción, sólo puede llegar a cobrar realidad como existencia histórico-universal. Existencia histórico-universal de los individuos, es decir, 
existencia de los individuos directamente vinculada a la historia universal. (Marx y Engels, 1974, pp. 37-38; énfasis en el original)

Esa dicotomía de lo real superando lo actual o "lo existente ahora" tiene lugar a escala global en una "historia universal", o sea, en el mercado mundial. Sin embargo, Marx era consciente de la existencia de varias lógicas heterogéneas que coexisten en esa historia:

\begin{abstract}
La burguesía somete el campo al imperio de la ciudad. Crea ciudades enormes, intensifica la población urbana en una fuerte proporción respecto a la campesina y arranca a una parte considerable de la gente del campo al cretinismo de la vida rural. Y del mismo modo que somete el campo a la ciudad, somete los pueblos bárbaros y semibárbaros a las naciones civilizadas, los pueblos campesinos a los pueblos burgueses, el Oriente al Occidente. (Marx y Engels, 1949, p. 77)
\end{abstract}

En Marx estas lógicas son conceptualizadas como un proceso continuo de superación. Tenemos aquí una triple analogía: campo/ciudad, semibárbaros o bárbaros /civilizados, Occidente/Oriente. La lógica del desarrollo del mercado mundial tiende a barrer las formas sociales atrasadas permitiendo la hegemonía de las más avanzadas.

Vemos entonces que, a pesar de tomar en cuenta lo que pasa en la periferia del naciente mercado mundial, la perspectiva teleológica sigue dominando el pensamiento de Marx como garantía de un horizonte comunista seguro. Las primeras brechas a su presupuesto vendrán de una pequeña modificación, cuando comience a suponer que la revolución podría ser desencadenada desde la periferia. Pero el sujeto no será ya necesariamente el proletariado, como vimos en el caso de Alemania: Marx comenzará a pensar que las formas sociales atrasadas pueden cumplir este papel desencadenante de la revolución en Occidente.

\title{
La revolución en China como desencadenante de la revolución en Europa
}

Instalado en Londres después del fracaso revolucionario del 48 Marx se encuentra sin una fuente de ingresos regular para sostener a su familia. Comienza ahí una colaboración periodística con The New York Daily Tribune. En uno de sus primeros 
artículos escribe sobre China, y muestra allí claramente cómo la aparición del mercado mundial en esta escala global no puede ser entendida como una suma de países con relaciones horizontales entre sí, sino como una verdadera interconexión en un único espacio, una única unidad, sin librarse de las contradicciones. Marx comienza el artículo citando implícitamente a Hegel al hablar de la "ley de la unidad de los contrarios". Lo original está en el hecho de que esos contrarios se relacionan en una escala global desde distancias nunca antes imaginadas:

Puede verse una brillante ilustración de si la "unidad de los contrarios" es un principio tan universal o no en el efecto que la revolución china parece producir en el mundo civilizado. Puede parecer un aserto muy extraño y paradójico el que la próxima rebelión de los pueblos de Europa y su próximo movimiento por la libertad republicana y la economía de gobierno dependa con más probabilidad de lo que está pasando ahora en el Imperio Celeste. (Marx y Engels, 1970, p. 9)

Marx continúa pensando que la revolución socialista tendrá lugar en los países más adelantados, pero ahora cree que podría ser causada por revueltas o revoluciones en la periferia. En aquel momento China se encontraba en una guerra civil de millones de muertos, que estaba afectando de manera considerable al comercio internacional. De alguna manera los pueblos más atrasados y las situaciones periféricas encontraban un papel propio que jugar en los cambios revolucionarios por los que debería atravesar la humanidad.

Ya no se trataba - como ocurría en el caso de Alemania y la revolución permanente- de una cuestión de rápida evolución para agotar las formas sociales atrasadas y alcanzar el nivel de desarrollo de los más avanzados. Ahora Marx reconocía un papel específico - aunque no socialista- que podía ser cumplido activamente por las formas sociales periféricas supuestamente condenadas a desaparecer. En este caso el papel consistía en activar la crisis mundial que sería el desencadenante de la revolución proletaria en Inglaterra. Si la revolución de 1848 debió fracasar porque las condiciones objetivas no estaban aún maduras - a pesar de que en la periferia pudieron observarse sus formas más avanzadas-, con el caso de China vemos que tales condiciones estaban interconectadas en el mercado mundial, de tal manera que la guerra civil china resultaba un factor desencadenante, sin necesidad de que la clase obrera se hubiera desarrollado allí. 


\title{
Bolivar y las independencias americanas
}

Pero tampoco estos reajustes que Marx hacía de sus expectativas teóricas parecían confirmarse claramente. Sus esperanzas estaban puestas en una nueva crisis mundial que conectara luchas tan distantes como las del proletariado inglés y el pueblo chino. De ahí que él y Engels se apresuren a predecir nuevas crisis mundiales para 1852, 1853 y 1855 basándose en proyecciones de la economía mundial (Mandel, 1967, p. 78). Pero la crisis tardaría más en llegar, y además, no lo haría con la fuerza que Marx esperaba. En este desesperante pasar del tiempo, el filósofo alemán comienza a percibir que la realidad - el orden empírico - no se comporta tal como predice la teoría - el orden lógico-. De ahí que en algunos casos extremos Marx adoptase una posición extremadamente defensiva, negando la realidad a lo existente. Un ejemplo especialmente interesante a estos efectos es la famosa biografía que hace de Bolívar ${ }^{4}$.

El hecho de que escribiese esa biografía fue un puro accidente histórico. Marx no buscó profundizar en la figura de Bolívar por sí mismo. Engels y él se dividieron la colaboración para la New American Cyclopaedia, y fue por azar que el de Tréveris acabó estudiando a Bolívar (Draper, 1968). La severidad con que Marx juzga al Libertador llega a resultar incomprensible. Si Bolívar fue una figura tan cobarde y miserable como se representa en dicha biografía, ¿cómo entender la influencia de ese hombre en las independencias latinoamericanas? El alemán era consciente del grado de violencia que se alcanzaba a percibir allí, tal como le reconoce a Engels en carta del 14 de febrero de 1858:

\begin{abstract}
Además Dana me pone reparos a causa de un artículo más largo sobre "Bolívar", porque estaría escrito en un partisan style, y exige mis authorities. Estas se las puedo proporcionar, naturalmente, aunque la exigencia es extraña. En lo que toca al partisan style, ciertamente me he salido algo del tono enciclopédico. Hubiera sido pasarse de la raya querer presentar como Napoleón I al canalla más cobarde, brutal y miserable. Bolívar es el verdadero Soulouque. (Marx y Engels, 1972, p. 98)
\end{abstract}

Marx compara a Bolívar con Soulouque, emperador de Haití entre 1848 y 1859, una figura que ya había usado para compararla con Napoleón III en "El 18 brumario”, en su famosa metáfora teatral de pensar la Historia como tragedia y como farsa.

4 En lo que sigue, me baso fundamentalmente en la brillante explicación que proporciona José Aricó (2009) sobre la relación de Marx con Bolivar. 
Esta comparación refleja el desprecio tan desmedido que sentía por Bolívar: le niega incluso el honor de ser comparado no ya con Napoleón sino incluso con Napoleón III — figura de por sí detestable para Marx-. Tan solo Soulouqe, figura aún más patética, es comparable con el Libertador.

Como señala Aricó, en la biografía de Bolívar podemos percibir "claramente la presencia de un prejuicio político firmemente enraizado" (2009, p. 161). En Marx continúa presente el hegelianismo, esa racionalidad de la Historia que estaría ausente en el caso de Hispanoamérica: los "pueblos sin historia”, que quedaban fuera de la "legalidad de la historia", de su racionalidad en desarrollo. Sin embargo, la explicación específica del tratamiento de Bolívar se encuentra, paradójicamente, en un intento de Marx por alejarse de Hegel y reafirmarse en su apuesta teórica. Debemos reconstruir este intento con cuidado.

En su Crítica a la Filosofía del derecho de Hegel, Marx hizo especial énfasis en la relación que Hegel supone entre Estado y sociedad civil. Este será luego el punto de partida para conectar a la sociedad civil con la "economía" y al Estado con la "política”. En la misma época en la que escribía sobre Bolívar también escribió el famoso "Prólogo" a la Contribución de la crítica de la economía política:

La primera tarea que emprendí con el objeto de resolver las dudas que me asediaban fue una revisión crítica de la filosofía del derecho de Hegel, un trabajo cuya introducción apareció en los Anales Franco-Alemanes, editados en París en 1844. Mi investigación desembocó en el resultado de que tanto las condiciones jurídicas como las formas políticas no podían comprenderse por sí mismas ni a partir de lo que ha dado en llamarse el desarrollo general del espíritu humano, sino que, por el contrario, radican en las condiciones materiales de vida, cuya totalidad agrupa Hegel, según el procedimiento de los ingleses y franceses del siglo XVIII, bajo el nombre de "sociedad civil", pero que era menester buscar la anatomía de la sociedad civil en la economía política. (Marx, 2008a, p. 4)

Marx no podía aceptar la posibilidad de un Estado que fuese el producto de la sociedad civil, o sea, de la nación. En el pensamiento de Hegel el Estado es el núcleo fundamental por ser esencia de un pueblo. Rechazando la propuesta de Hegel sobre esa relación Estado-sociedad civil Marx acabó reforzando la asimetría entre “economía” y “política” y reduciendo la política a lo arbitrario o lo irracional en los 
casos en los que no conseguía explicar lo político mediante el recurso a la sociedad civil. También podemos comprender este como un caso de relación general entre "materia" e "idea". La concepción del Estado hegeliano como un ente autónomo y productor de lo material es esa concepción combatida por Marx y mostrada como perversidad en el caso del bonapartismo del in Imperio francés. Bolívar no sería más que una repetición de ese bonapartismo: una lógica que no es una emanación de la sociedad civil resulta necesariamente autoritaria y arbitraria, irracional, y por eso, una "falsa forma".

En el momento de estudiar la vida de Bolívar cristaliza esta disputa con Hegel como opción teórica. Para Marx resultaba preciso mostrar al Libertador como una figura histórica sin ninguna racionalidad precisamente porque parecía confirmar lo que quería combatir en Hegel.

\section{India y el desarrollo industrial más allá de Europa}

Los estudios de Marx sobre la colonización de la India son quizás el mejor ejemplo de cómo para él las formas más desarrolladas - las capitalistas - superan y desplazan a las formas más atrasadas.

Recordemos el "Prólogo" a El capital de 1867, en el que Inglaterra es presentada como el espejo de una Alemania todavía sin industrializar: "Se trata de estas leyes mismas, de esas tendencias que operan y se imponen con férrea necesidad. El país industrialmente más desarrollado no hace sino mostrar al menos desarrollado la imagen de su propio futuro" (Marx, 1975a, p. 7).

En este caso Marx está pensando en Inglaterra y Alemania, pero lo importante aquí es esa "operación teórica” expresada en el latinismo de te fabula narratur:

Pero si el lector alemán se encogiera farisaicamente de hombros ante la situación de los trabajadores industriales o agrícolas ingleses, o si se consolara con la idea optimista de que en Alemania las cosas distan aún de haberse deteriorado tanto, me vería obligado a advertirle: De te fabula narratur! [¡A ti se refiere la historia!]. (1975a, p. 7)

Ese racionalismo no es casual: representa la lógica implícita en Marx de la sucesión de formas sociales. 
En una carta a Engels fechada el 2 de junio de 1853 Marx considera que la verdadera diferencia entre Occidente y Oriente es la propiedad de la tierra. El feudalismo dio lugar a una propiedad privada, mientras que en Oriente la propiedad colectiva o comunitaria continuó existiendo. Esa ausencia de propiedad privada sería un obstáculo para el desarrollo de las formas capitalistas. Ese es el origen conceptual del "modo de producción asiático", que Marx incluiría en el "Prólogo" de la Contribución. Incluso reconociendo los cambios que tuvieron lugar con la colonización británica en India, ahí se mantuvieron las condiciones sociales más básicas. Solo como consecuencia del comercio internacional las viejas estructuras sociales comenzaban a ser destruidas:

Estas pequeñas formas estereotipadas de organismo social han sido destruidas en su mayor parte y están desapareciendo, no tanto por culpa de la brutal intromisión del recaudador británico de contribuciones o del soldado británico, como por la acción del vapor inglés y de la libertad de comercio inglesa. Estas comunidades de tipo familiar tenían por base la industria doméstica, esa combinación peculiar de tejido a mano, hilado a mano y laboreo a mano, que les permitía bastarse a sí mismas. La intromisión inglesa, que colocó al hilador en Lancashire y al tejedor en Bengala, o que barrió tanto al hilador hindú como al tejedor hindú, disolvió esas pequeñas comunidades semibárbaras y semicivilizadas, al hacer saltar su base económica, produciendo así la más grande, y, para decir la verdad, la única revolución social que jamás se ha visto en Asia. (Marx y Engels, 1970, p. 23)

El ejemplo paradigmático será el ferrocarril. La introducción del tren cambiaría tendencialmente toda la estructura social de India:

Ya sé que la burguesía industrial inglesa trata de cubrir la India de vías férreas con el exclusivo objeto de abaratar el transporte del algodón y de otras materias primas necesarias para sus fábricas. Pero si introducís las máquinas en el sistema de locomoción de un país que posee hierro y carbón, ya no podréis impedir que ese país fabrique dichas máquinas. No podréis mantener una red de vías férreas en un país enorme, sin organizar en él todos los procesos industriales necesarios para satisfacer las exigencias inmediatas y corrientes del ferrocarril, lo cual implicará la introducción de la maquinaria en otras ramas de la industria que no estén directamente relacionadas con el transporte ferroviario. El sistema ferroviario se convertirá por tanto en la India en un verdadero precursor de la industria moderna. (Marx y Engels, 1970, p. 51) 


\section{México y Estados Unidos: las relaciones internacionales e interestatales}

La transformación más o menos súbita de la actitud de Marx en lo que se refiere a la relación entre Estados Unidos y México coincide con la guerra de Secesión (1861-1865). En un principio tanto Marx como Engels habían visto con buenos ojos el expansionismo norteamericano, y en gran parte por la satisfacción de que fuera a costa de México 5 . En un artículo de 1848, titulado "La tutela de los Estados Unidos" (Marx y Engels, 1972), Engels se muestra visiblemente alegre por el nuevo control de Estados Unidos sobre Texas y California. Por supuesto, sabe que el único beneficiado será la burguesía, pero lo considera un avance.

Será con la guerra civil norteamericana que Marx tome profunda conciencia de lo que realmente estaba en juego en la relación entre Estados Unidos y México: no la sucesión teleológica de formas sociales más modernas que eliminan otras más atrasadas, sino el "problema esclavista". O sea, la estrategia de las élites del sur de Estados Unidos, que necesitaban expandirse hacia el oeste (California y el Pacífico) y hacia el sur (México).

Con la guerra de secesión Marx entendió que la política expansionista de Estados Unidos estuvo siempre secuestrada por los intereses del sur esclavista, incluida la guerra contra México por Texas (1846-1848). La esclavitud, por tanto, no era una anomalía, una rara forma social empleada en un caso muy específico del "mercado mundial”, sino que se presentaba como un verdadero modelo de desarrollo para una nación moderna. Fue este reconocimiento de que formas aparentemente del pasado podían imponerse como una vía de desarrollo de futuro compatible con el capital lo que iba a conmover hasta sus cimientos las ideas de Marx sobre las formas sociales. En El capital el alemán reconocerá explícitamente la relación estrecha entre desarrollo industrial y esclavitud en Estados Unidos:

No cabe duda alguna, por ejemplo, de que el avance arrollador de la hilandería algodonera no sólo hizo crecer como planta de invernadero el cultivo del algodón en los Estados Unidos, y con ese cultivo la trata de africanos, sino que a la vez convirtió la cría de esclavos en el principal negocio de los llamados estados esclavistas limítrofes. (Marx, 1975a, p. 540)

5 Asi, en una carta de Marx a Engels fechada el 2 de diciembre de 1854, el primero no tiene ningún pudor en afirmar que, aunque los españoles fuesen unos degenerados, los mexicanos eran aún peores (Marx y Engels, 1972, p. 203). 
Según este nuevo raciocinio, el desarrollo de las formas sociales para Marx ya no sería necesariamente el fin de las formas previas. De hecho, el desarrollo de las formas capitalistas puede ser una condición para la reproducción de las formas históricas que parecían ya superadas, como el esclavismo. El capitalismo podía ser interpretado, entonces, como la coexistencia de formas sociales heterogéneas, pero coherentes con un proceso general de acumulación de capital.

Vemos que se trata de mecanismos extraeconómicos de acumulación, pero capitalistas por estar insertos en el proceso de valorización del capital. Ir percibiendo esta correlación y dependencia de formas sociales heterogéneas - que ya no parecen eliminarse, sino potenciarse - era incompatible con un optimismo ingenuo sobre la expansión de Estados Unidos.

\section{Irlanda y sus luchas nacionales}

Si hasta 1848 Marx y Engels mostraban su solidaridad con las naciones oprimidas en Europa, será a partir de la década de 1850 cuando abiertamente rechacen el sentimentalismo político y comiencen a subordinar las luchas nacionalistas al objetivo general de la revolución socialista. El derecho a la independencia no puede ser considerado, desde esta perspectiva, como un derecho abstracto y universal, sino como una estrategia política dentro de la perspectiva de la revolución.

Esa perspectiva necesitaba imaginar al proletariado como una clase universal. El cuestionamiento de las ideas de Marx vino del cuestionamiento de esa universalidad del proletariado. Así comenzó a cristalizar esa idea de un "desarrollo desigual”, de que las formas heterogéneas no siempre son contradictorias, como acabamos de ver en el caso del esclavismo en Estados Unidos. Reflexionando sobre el saqueo al que Inglaterra sometía a Irlanda Marx avanzó considerablemente sobre la posición que había mantenido antes acerca de la ocupación británica de India, como vemos en la carta a Engels del 2 de noviembre de 1867:

Antes creía que era imposible separar a Irlanda de Inglaterra. Ahora lo considero inevitable, aunque después de la separación pueda sobrevenir una federation [federación] [...]. La dominación extranjera no tiene en ningún otro país europeo esta forma directa de expropiación a los nativos. (Marx y Engels, 1979, p. 138) 
No se trata de reflexiones aisladas. En ese mismo momento se estaba publicando la primera edición de El capital, en la que Marx asume un cierto "desarrollo desigual" que liga dos polos opuestos del desarrollo, como Irlanda e Inglaterra:

Esta ley produce una acumulación de miseria proporcionada a la acumulación de capital. La acumulación de riqueza en un polo es al propio tiempo, pues, acumulación de miseria, tormentos de trabajo, esclavitud, ignorancia, embrutecimiento y degradación moral en el polo opuesto, esto es, donde se halla la clase que produce su propio producto como capital.

Los economistas han expuesto de maneras diversas esos caracteres antagónicos de la acumulación capitalista, aunque los confundan con fenómenos en parte análogos, sin duda, pero esencialmente diferentes, que se dan en modos de producción precapitalistas. (Marx, 1975a, p. 805)

Marx advierte explícitamente sobre el peligro de confundir los efectos de la acumulación con fenómenos que sean simplemente precapitalistas. Ciertamente, existen formas sociales que perduran, pero pueden también continuar reproduciéndose al subordinarse al proceso general de acumulación. De ahí que, en adelante, para Marx y Engels la emancipación de los irlandeses pasase a ser la condición necesaria para la emancipación del proletariado inglés.

La relación entre las luchas de clases y las luchas nacionales cambió a la luz de sus nuevas concepciones teóricas. No obstante, en el plano político Marx todavía estaba pensando en un proceso muy similar a ese que durante el siglo $\mathrm{xx}$ fue conocido como “desarrollo nacional". En una carta a Engels fechada el 30 de noviembre de 1867, el de Tréveris adelanta incluso los puntos básicos del programa para lo que podría ser una Irlanda independiente: primero, el autogobierno y la independencia; segundo, una revolución agraria (reforma agraria) que transformase la propiedad feudal, y tercero, un proteccionismo comercial que aislara a Irlanda del mercado mundial.

En cualquier caso, estamos ya muy lejos de una fe ciega en que las fuerzas desatadas en el mercado mundial lleven por sí mismas a la superación de unas formas sociales atrasadas por otras avanzadas. En la nueva concepción teórica existe margen de maniobra en la historia. 


\section{La comuna rural y las otras bases para la revolución}

En principio, la posición que pudiera tener Marx sobre Rusia no debería ser muy diferente a la del caso de India. De hecho, en una carta al populista ruso Danielson fechada el 22 de septiembre de 1892 Engels dedicaba a Rusia casi las mismas palabras de Marx sobre el papel modernizador del ferrocarril en India:

La producción industrial significa hoy día gran industria, vapor, electricidad, hiladoras y telares mecánicos, y finalmente máquinas que fabrican máquinas. A partir del día [en] que Rusia importó los ferrocarriles, la introducción de esos medios modernos de producción fue inevitable. Ustedes tienen que poder fabricar sus propias locomotoras, vagones, vías, y esto sólo puede hacerse en forma barata si son capaces de construir en el país esas cosas que desean reparar. A partir del momento en que la guerra se transformó en una rama de la gran industria (barcos acorazados, artillería de cañones rayados, de tiro rápido y de repetición, rifles de repetición, balas recubiertas de acero, pólvora sin humo, etcétera), la gran industria, sin la cual todas estas cosas no se pueden hacer, tornose una necesidad política. No pueden tenerse todas estas cosas $\sin$ una manufactura metalúrgica altamente desarrollada. Y esta manufactura no puede existir sin un correspondiente desarrollo de todas las demás ramas de la manufactura, en especial la textil. (Marx, Engels y Danielson, 1983, p. 288)

En esta ocasión Engels estaba siendo fiel representante del socialismo de la II Internacional ${ }^{6}$. No obstante, antes de morir Marx tanto él como Engels habían reconocido la posibilidad de un proceso sui generis en Rusia. En el nuevo prefacio a la edición rusa del Manifiesto de 1882, firmada por ambos, dice:

¿Puede la obshchzna [comuna rural] rusa, forma, aunque muy erosionada, de la primitiva propiedad comunal de la tierra, pasar directamente a la forma superior, comunista, de propiedad comunal? ¿O bien debe pasar primero por el mismo proceso de disolución que caracteriza el desarrollo histórico en Occidente? Hoy existe una sola respuesta. Si la revolución rusa se convierte

6 Aunque, para ser coherentes con la metodología aqui empleada, deberiamos entender también la II Internacional como un "campo de fuerzas" atravesado por contradicciones y diversidad ideológica. Como ejemplo, basta considerar las reflexiones de su principal ideólogo, Karl Kautsky, sobre Rusia tras la Revolución de 1905. Como Gaido y Ávila (2015) han mostrado, el posicionamiento de Kautsky se alejaba en algunos puntos clave de la concepción lineal del desarrollo de la filosofía de la historia, sobre todo en lo que se refiere a la táctica y al conflicto político. 
en una señal para la revolución proletaria en Occidente, de tal modo que una complemente a la otra, entonces la propiedad campesina comunal de la tierra podrá servir como punto de partida para un desarrollo comunista. (citados en Shanin, 1990, p. 177)

A lo largo de su vida Marx mantuvo relaciones con tres generaciones de revolucionarios rusos, pero solamente en sus últimos años comenzó a estudiar a Rusia en profundidad (Deutscher, 1970). Su interés por el tema fue tan grande que Engels en el prólogo al libro iII de El capital nos comparte que llegó a ser una obsesión para su amigo. Dos documentos nos permiten conocer mejor la posición que Marx estaba intentando aclarar en esa última etapa de su vida. El primero es la carta de 1877 dirigida a una revista rusa, la Otiechéstvennie Zapiski. En esta, intenta desligarse de un fatalismo historicista y unidireccional. El segundo texto es la carta de respuesta, con sus borradores, a Veza Zasúlich, de 1881. Los dos documentos tienen en común la dificultad de Marx para expresar una alternativa teórica a esa unidireccionalidad histórica que a la sazón criticaba.

En los borradores a la carta de respuesta a Zasúlich, Marx admite que el orden teórico expuesto en El capital no es necesariamente el orden histórico: "Los que creen que la disolución de la propiedad comunal es una necesidad histórica en Rusia no pueden, bajo ninguna circunstancia, probar esa necesidad a partir de mi descripción del curso inevitable de las cosas en Europa occidental" (citado en Shanin, 1990, p. 132).

Para justificar la distinción entre ambos órdenes Marx piensa en dos ámbitos. Primero, en la lógica propia del capital como relación social. Segundo, en la descripción de los fenómenos históricamente ocurridos en Occidente. Si el primero (la lógica de la relación social del capital) fuese simplemente reflejo del segundo (una experiencia histórica europea), entonces El capital sería una obra teórica sin mayor interés que el de sintetizar una historia irrepetible. Sabemos que esa no es la perspectiva de Marx porque, como acabamos de ver, este negaba que la experiencia histórica de Europa fuese generalizable sin negar por ello la validez teórica de $E l$ capital. Se deduce que la relación entre la experiencia histórica (orden empírico) y lo teórico (orden lógico) es más compleja porque "es necesario descender de la teoría pura a la realidad rusa" (citado en Shanin, 1990, p. 147). 
"Descender" significa que no podemos entender lo histórico sin lo teórico, pero no podemos reducir lo teórico a una expresión sintética de lo histórico. Existe cierto grado de autonomía de lo histórico frente a lo teórico y de este frente a aquel. Si en "El método de la economía política" Marx usaba una imagen hegeliana de "elevarse" de lo abstracto a lo concreto, ahora usa una imagen distinta, la de "descender" de lo teórico a la realidad histórica.

En realidad, son dos momentos de un mismo proceso. La elevación de lo abstracto a lo concreto permite entender la racionalidad de los elementos ya presentes en la realidad histórica. Si no tuviéramos ese orden teórico, las formas sociales solo serían conocidas por una descripción inductiva que en la herencia racionalista sabemos que no podría ser considerada como un conocimiento satisfactorio. A pesar de eso, las relaciones concretas entre las formas sociales heterogéneas - la dinámica histórica- no pueden ser explicadas por un modelo teórico como El capital, y deben ser entendidas en su particularidad histórica. En la carta de 1877 Marx decía:

De modo que acontecimientos de una semejanza extraordinaria, que tienen lu-
gar en diferentes contextos históricos, llevan a resultados totalmente diferentes.
Estudiando cada uno de esos desarrollos por separado, y luego comparándolos,
se puede descubrir fácilmente la clave del fenómeno. Pero nunca se alcanzará
el éxito con la llave maestra de una teoría histórico-filosófica general, cuya
suprema virtud consiste en ser suprahistórica. (citado en Shanin, 1990, p. 174)

La "clave del fenómeno" es esa racionalidad compartida, o sea, aquello basado en una explicación teórica que no equivale a suponer explicaciones históricas generales. Necesitamos explicaciones históricas que consigan integrar la "explicación teórica" como uno de los momentos de la explicación. De ahí que en su carta a Zasúlich Marx dijera que "el análisis de El capital, por tanto, no aporta razones ni en pro ni en contra de la vitalidad de la comuna rusa” (citado en Shanin, 1990, p. 160).

En el final de su vida la teoría para Marx parece ser aquello que muestra la posibilidad de transformación al mostrar la presencia de lo racional y lo irracional en lo empírico. Pero no predice el curso o el camino necesario porque esa evolución es producida únicamente por las condiciones de las luchas de clases. Marx estaba llegando a asimilar lo que había percibido en Darwin: que hay evolución, cambio, superación de unas formas por otras, pero no un orden prestablecido, y por tanto, no una teleología de la Historia. 


\section{Conclusiones}

En esta breve reconstrucción hemos mostrado la diversidad de posiciones de Marx sobre la evolución del capitalismo en la periferia del mercado mundial. Mostramos que, en el comienzo, él sostenía todavía una lógica casi hegeliana de superación de unas formas por otras en un camino teleológico hasta el comunismo. Sin embargo, la evolución de las luchas de clases y de los diversos eventos históricos lo convenció de superar la perspectiva teleológica propia del pensamiento de Hegel. De ahí en adelante, Marx enfrentó con flexibilidad sucesos como la supervivencia de la esclavitud en Estados Unidos, el movimiento nacional en Irlanda y, sobre todo, el papel de la comuna rural rusa en una posible transición al socialismo, ninguno de los cuales involucró formas capitalistas. Esos casos le sirvieron para trabajar en una perspectiva no teleológica que no por eso descartaba el horizonte o la meta comunista.

De alguna manera, Marx llegó a resolver ese problema gracias a las contradicciones expuestas desde la periferia del capitalismo, pero eso nos lleva a considerar una relación epistemológica poco común entre la teoría y la experiencia histórica: la teoría no tiene el papel de proveer una explicación total de los fenómenos, sino la de marcar las posibilidades de transformación de la realidad histórica por parte de la agencia humana, es decir, por medio de la lucha de clases.

\section{Referencias}

Aricó, J. M. (2009). Marx y América Latina. Buenos Aires: FCE.

Deutscher, I. (1970). Marx, Engels y Rusia. En Herejes y renegados (pp. 82-92). Barcelona: Ariel.

Draper, H. (1968). Carlos Marx y Simón Bolívar: apunte sobre el liderazgo autoritario en un movimiento de liberación nacional. Desarrollo Económico, 8(30/31), 293-311.

Dussel, E. (2014). 16 tesis de economía política: interpretación filosófica. México: Siglo XXI.

Engels, F. (1974). Contribución a la historia de la Liga de los Comunistas. En K. Marx y F. Engels, Obras escogidas. Tomo III (pp. 184-202). Moscú: Progreso. 
Gaido, D. y Ávila, P. (2015). Fuerzas motrices y perspectivas de la revolución rusa, Karl Kautsky, 1906. Izquierdas, 24, 246-283.

Lichtheim, G. (1961). Marxism: An historical and critical study. Nueva York: Frederick A. Prager.

Mandel, E. (1967). La formación del pensamiento económico de Marx. México: Siglo XXI.

Marx, K. (1968). Introducción a la crítica de la Filosofía del derecho de Hegel. En G. F. Hegel, Filosofía del derecho (pp. 7-22). Buenos Aires: Claridad.

Marx, K. (1975a). El capital. Crítica de la economía política. Libro I: el proceso de producción de capital. México: Siglo xxI.

Marx, K. (1975b). Cartas a Kugelmann. La Habana: Editorial Ciencias Sociales.

Marx, K. (1985a). Carta a Ruge, septiembre de 1843. En K. Marx, Obras fundamentales I. Escritos de juventud (pp. 457-460). México: FCE.

Marx, K. (1985b). Glosas críticas al artículo "El rey de Prusia y la reforma social. Por un prusiano". En K. Marx, Obras fundamentales I. Escritos de juventud (pp. 505-521). México: FCE.

Marx, K.. (2008a). Prólogo. En K. Marx, Contribución a la crítica de la economía política (pp. 3-7). Madrid: Siglo XxI.

Marx, K.. (2008b). Introducción a la crítica de la economía política. En K. Marx, Contribución a la crítica de la economía política (pp. 281-313). México: Siglo XXI.

Marx, K. y Engels, F. (1949). Biografía del Manifiesto comunista. México: Editorial México.

Marx, K. y Engels, F. (1970). Acerca del colonialismo (artículos y cartas). Moscú: Progreso.

Marx, K. y Engels, F. (1972). Materiales para la historia de América Latina. Córdoba (Argentina): Pasado y Presente.

Marx, K. y Engels, F. (1973). Mensaje del Comité Central a la Liga de los Comunistas. En Obras escogidas. Tomo I (pp. 179-189). Moscú: Progreso. 
Marx, K. y Engels, F. (1974). La ideología alemana. Barcelona: Grijalbo.

Marx, K. y Engels, F. (1975). Cartas sobre las ciencias de la naturaleza y las matemáticas. Barcelona: Anagrama.

Marx, K. y Engels, F. (1979). Imperio y colonia. Escritos sobre Irlanda. México: Pasado y Presente.

Marx, K. y Engels, F. (1983). Cartas sobre “El capital”. La Habana: Editorial Política.

Marx, K., Engels, F. y Danielson, N. F. (1981). Correspondencia (1868-1895). México: Siglo XXI.

Rendueles, C. (2012). Introducción. En K. Marx, Escritos sobre materialismo histórico (pp. 9-32). Madrid: Alianza.

Shanin, T. (ed.) (1990). El Marx tardío y la vía rusa. Marx y la periferia del capitalismo. Madrid: Revolución.

Tarcus, H. (2008). ¿Es el marxismo una filosofía de la historia? Marx, la teoría del progreso y la "cuestión rusa". Andamios, 4(8), 7-32. 